\title{
Insult, Aggression, and the Southern Culture of Honor: An "Experimental Ethnography"
}

\author{
Dov Cohen \\ University of Illinois at Urbana-Champaign
}

Brian F. Bowdle

Northwestern University

\author{
Richard E. Nisbett \\ University of Michigan (Ann Arbor) \\ Norbert Schwarz \\ University of Michigan (Ann Arbor)
}

\begin{abstract}
Three experiments examined how norms characteristic of a "culture of honor" manifest themselves in the cognitions, emotions, behaviors, and physiological reactions of southern White males. Participants were University of Michigan students who grew up in the North or South. In 3 experiments, they were insulted by a confederate who bumped into the participant and called him an "asshole." Compared with northerners - who were relatively unaffected by the insult-southerners were (a) more likely to think their masculine reputation was threatened, (b) more upset (as shown by a rise in cortisol levels), (c) more physiologicaliy primed for aggression (as shown by a rise in testosterone leveis), (d) more cognitively primed for aggression, and (e) more likely to engage in aggressive and dominant behavior. Findings highlight the insult-aggression cycle in cultures of honor, in which insults diminish a man's reputation and he tries to restore his status by aggressive or violent behavior.
\end{abstract}

Approximately 20,000-25,000 Americans will die in homicides this year, and tens of thousands more will be injured in stabbings or gunfights that could have ended in death. In about half of the homicides for which police can find a cause, the triggering incident seems argument- or conflict-related (Fox \& Pierce, 1987); and, in many of these cases, this triggering incident might be classified as "trivial" in origin, arising from a dispute over a small amount of money, an offensive comment, or a petty argument.

Such incidents, however, are not trivial to the participants in them. Rather, the participants behave as if something important

Dov Cohen, Department of Psychology, University of Illinois at Urbana-Champaign; Richard E. Nisbett and Norbert Schwarz, Department of Psychology, University of Michigan (Ann Arbor); Brian F. Bowdle, Department of Psychology, Northwestern University.

We are indebted to the following people for their heip with the conceptual development and execution of the experiments: Jessica Berns, Carissa Bowles, Eli Cohen, Lisa Cohen, Ronna Cohen, Mechele de Avila, James Dabbs, Amie Eigner, Phoebe Ellsworth, Jennifer Euster, Tangic Fry, Becky Gastman, Cori Hardy, James Hilton. David Howell, Kerrie Johnson, Stephanie Kitchen, Fred Lennox, Sheri Levy, Andy Modigliani, Sean O'Neil, Sangita Patel, Chris Powers, Jasmin Riad, Frank Rowan, Jeremy Shook, Cassie Slisher, Pam Smith, Jon Steinfeld, Kent Talcott, Kevin Taylor, Ken Visser, Tomica Williams, and Phil Wills. Andrew Reaves made belpful comments about an earlier draft. This work was supported in part by a Russell Sage Foundation Grant and by National Science Foundation Grant DBS-9121346.

Correspondence concerning this article should be addressed to Dov Cohen, Department of Psychology, Lniversity of Illinois, 603 East Daniel Street, Champaign, Illinois 61820. is at stake (Daly \& Wilson, 1988). They act as if they were members of what anthropologists call a culture of honor, in which even small disputes become contests for reputation and social status. The United States is home to several subcultures holding such norms (Anderson, 1994; Fischer, 1989; Gilmore, 1990; Guerra, in press; McCall, 1994; McWhiney, 1988; Peristiany, 1965; Pitt-Rivers, 1968; Wolfgang \& Ferracuti, 1967). The research presented here is a first attempt at what might be called an experimental ethnography of one such subculture within the United States-that of the southern White male.'

\section{Historical Background}

For centuries, the American South has been regarded as more violent than the North (Fischer, 1989). Over the years, historians, social scientists, and other observers have developed a number of explanations for this, drawing on such facts about the South as its higher temperature, its poverty, and its history of slavery. There is evidence to support all these explanations, and they have been dealt with more fully elsewhere (Cohen, 1996; Cohen \& Nisbett, 1994; Nisbett, 1993; Nisbett \& Cohen, 1996; Reaves \& Nisbett, 1994). We think the best single explanation

\footnotetext{
'The South is not the only section of the country to which we can look for culture-of-honor norms. The West has a history quite similar to the South, and residues of the frontier violence that characterized the West can still be secn in the higher homicide rates of the West today (Kowalski \& Peete, 1991; Lee, 1993). For the experiments in this article. we chose to focus on the South instead of the West because this has been the subject of much of our other research (Cohen \& Nisbett, 1994; Nisbett, 1993; Reaves \& Nisbett, 1994).
} 
has to do with the South being home to a version of the culture of honor, in which affronts are met with violent retribution.

Historians and other observers have often noted that, in the South, men have had to take action against insults or else lose status before their family and peers (McWhiney, 1988; WyattBrown, 1982). As Fischer (1989) noted,

From an early age, small boys were taught to think much of their own honor and to be active in its defense. Honor in this society meant a pride of manhood in masculine courage, physical strength, and warrior virtue. Male children were trained to defend their honor without a moment's hesitation-lashing oul against their challengers with savage violence. (p. 690)

Originally, there were good historic and economic reasons for such norms to take hold in the South. For one, the economy of the South was initially based to a large extent on herding (McWhiney, 1988), and cultural anthropologists have observed that herding cultures the world over tend to be more approving of certain forms of violence (J. K. Campbell, 1965; Edgerton, 1971; Peristiany, 1965). Herdsmen must be willing to use force to protect themselves and their property when law enforcement is inadequate and when one's wealth can be rustled away. The settlers of the South came primarily from herding economies on the fringes of Britain, where lawlessness, instability, political upheaval, and clan rule had been present for centuries (Fischer, 1989; McWhiney, 1988). The people from the border country of Britain were forced to be self-reliant in their pursuit of justice, and they brought with them this tradition as they settled the lawless frontier South. As Fischer (1989) wrote,

In the absence of any strong sense of order as unity, hierarchy, or social peace, backsettlers shared an idea of order as a system of retributive justice. The prevailing principle was lax talionis, the rule of retaliation. It held that a good man must seek to do right in the world, but when wrong was done to him, he must punish the wrongdoer himself by an act of retribution that restored order and justice in the world. (p. 765)

If the ethic of self-protection had been adaptive in Britain, the frontier conditions of the South and the vulnerability of southerners to the theft of their herds and other lawlessness probably reinforced the self-reliant stance. Law enforcement in the frontier South was either inadequate, corrupt, or just too far away (Brown, 1969; Gastil, 1971; Ireland, 1979; McWhiney, 1988). So, as a North Carolina proverb put it, every man "should be sheriff on his own hearth" (Fischer, 1989, p. 765).

Such conditions perpetuated the culture of honor in the South, as it became important to establish one's reputation for toughness-even on matters that might seem small on the surface. If one had been crossed, trifled with, or affronted, retribution had to follow as a warning to the community. Defense of honor can be an important part of defense of self, as Daly and Wilson ( 1988 ) observed:

A seemingly minor affront is not merely a "stimulus" to action, isolated in time and space. It must be understood within a larger social context of reputations, face, relative social status, and enduring relationships. Men are known by their fellows as "the sort who can be pushed around" or "the sort who won't take any shit," as people whose word means action and people who are full of hot air, as guys whose girlfriends you can chat up with impunity or guys you don't want to mess with. (p. 128)
In the Old South, allowing oneself to be pushed around or affronted without retaliation amounted to admitting that one was an easy mark and could be taken advantage of. As PittRivers (1968) noted, "Whenever the authority of law is questioned or ignored, the code of honor re-emerges to allocate the right to precedence and dictate the principles of conduct" (cited in Ayers, 1984, p. 275).

\section{Persistence of the Culture of Honor}

Though frontier conditions in the South disappeared and the herding economy has become less and less important, cultureof-honor norms appear to have persisted into this century. Brearley (1934), for example, argued that in much of the South of his day it was impossible to convict someone of murder if (a) the killer had been insulted and ( $b$ ) he had warned the victim of his intent to kill if the insult were not retracted or compensated.

Nisbett and colleagues recently have shown that violence stemming from culture-of-honor norms is still part of the southern legacy today (Nisbett, 1993; Nisbett \& Cohen, 1996; Nisbett, Polly, \& Lang, 1994; Reaves \& Nisbett, 1994). White male homicide rates of the South are higher than those of the North, and the South exceeds the North only in homicides that are argument- or conflict-related, not in homicides that are committed while another felony, such as robbery or burglary, is being performed. Such findings are consistent with a stronger emphasis on honor and protection in the South.

Cohen and Nisbett (1994) came to similar conclusions about a southern culture of honor in analyzing data from major national surveys. They showed that the South was more approving of particular types of violence and not of others. The South's approval of violence seemed limited to violence used for selfprotection, to respond to an insult, or to socialize children. Thus, although southern white males were not more likely to endorse statements about violence in general ("Many people only learn through violence"), they were more willing to endorse violence when it was used to protect ("A man has the right to kill to defend his house") or to answer an affront (approving of a man punching a stranger who "was drunk and bumped into the man and his wife on the street"). Southern white males were also more likely to stigmatize men, described in brief scenarios, who did not respond with violence, criticizing them for being "not much of a man" if they failed to fight or shoot the person who challenged or affronted them. Such results suggest that southern white male approval of violence is produced by culture-of-honor norms.

The culture seems to be perpetuated as well by the institutions of the South. Cohen (1996) argued that culture-of-honor norms are embodied in the laws and social policies of southern states-as reflected in looser gun control laws, less restrictive self-defense statutes, and more hawkish voting by federal legislators on foreign policy issues, for example. In two field experiments, Cohen and Nisbett (1995) showed that southern institutions, such as employers and the media, may perpetuate culture-of-honor norms by being less likely to stigmatize violence in defense of honor and more likely to see it as justifiable or sympathetic.

In the work presented here, we supplement the attitude, homicide rate, law and social policy, and field experimental evidence with experimental evidence from the laboratory. In these labora- 
tory experiments, we examined whether even college students who are from the South subscribe to culture-of-honor norms, and we explored how these norms might manifest themselves in the cognitions, emotions, behaviors, and physiological reactions of our participants. The overarching theme of these experiments was the importance of an affront to southern white males and their need to respond to it. If southerners subscribe to a culture of honor and northerners do not, the reactions of northern and southern participants to an insult should differ in predictable ways. Compared with northerners, southerners should be (a) more likely to view an insult as damaging to their status and reputation, (b) more upset (emotionally and physiologically) by the insult, and (c) more prepared (cognitively, physiologically, and behaviorally) for aggressive and dominant behavior after being insulted. The present studies were designed to test these hypotheses.

When we refer to southerners and northerners, we refer only to the particular populations we have studied to date, namely nonHispanic white males from the North and from the South of the United States. It is these populations for which extensive anthropological and historical literature indicates there are substantial differences with respect to culture-of-honor norms. When we refer to northerners and southerners participating in the experiments described below, we are using this as a shorthand way of referring to students at the University of Michigan meeting these restricted definitions.

Because our sample is limited to students at the University of Michigan, it is also certainly not representative of all white male northerners and southerners. The students-both northern and southern-come from families that are well off financially. (In Experiment 3, the median income for northerners was between $\$ 80,000$ and $\$ 90,000$; for southerners it was between $\$ 90,000$ and $\$ 100,000$ ). The southerners may be unusual in that they have chosen to leave the South at least temporarily and come to school in the North. We suspect both of these factors work against us and that regional differences would be bigger if representative samples of northerners and southerners were examined. Thus, our sample probably provides for a rather conservative test of our hypotheses.

The three experiments we report all included the same basic manipulation: A confederate of the experimenter bumps into the unsuspecting participant as he walks down a hallway and calls the participant an "asshole." The three experiments focused on the different behavioral, cognitive, emotional, and physiological effects of the insult.

\section{Experiment 1}

In Experiment 1 we examined the effect of the insult on the immediate emotional reaction of the participant and on subsequently expressed hostility during the rest of the experiment. Subsequent hostility was assessed with a word-completion task, a face-rating task, and a neutral scenario-completion task to see if the participant would project his anger onto these stimuli. We also assessed hostility by having the participant complete the ending of a scenario that involved affront and sexual challenge. These procedures allowed us to examine whether (a) relatively neutral stimuli would bring out aggression after priming by the insult or (b) only subsequent stimuli that also involve affront or challenge would bring out aggression. In either case, a positive result calls for an interaction effect of regional origin and insult, with southerners reacting with more aggression after an insult than northerners.

Our theory led us to predict that this interaction would definitely be obtained when subsequent stimuli involve issues of insult or challenge. However, it was an open question whether the interaction would also be obtained for ambiguous or neutral stimuli. We did not make predictions regarding whether the interaction would occur on the face rating, word completion, or neutral scenario task. We believed, however, that it would be informative to examine these variables in an exploratory way to see how specific or general the effect of the insult was.

\section{Method}

The experiment involved a $2 \times 2$ design with participant's region of origin (North vs. South) as one variable and condition (insulted vs. not insulted) as the other variable.

\section{Participants}

Participants were 83 University of Michigan white male undergraduates ( 42 northern, 41 southern) who were recruited by telephone and paid $\$ 5$ for their time. Students who had lived in the South for a period of at least 6 years were considered southern. The South was defined as census divisions 5, 6, and 7. This includes the states of Delaware, Maryland, West Virginia, Virginia, North Carolina, South Carolina, Georgia, Florida, Kentucky, Tennessee, Alabama, Mississippi, Arkansas, Oklahoma, Louisiana, and Texas. In this experiment-as in Experiments 2 and 3-students from Washington, DC and from towns we could identify as its immediate suburbs were excluded, because DC is probably not representative of either northern or southern culture. ${ }^{2}$ All other students were considered northern.

So that all students would be equated at least with respect to whether they had self-selected to attend school in another state, all participants were non-Michigan residents. On average, southern students had spent $87 \%$ of their lives in the South, whereas northern students had spent only $4 \%$ of their lives in the South. Jewish students were excluded because we hypothesized that Jewish culture might dilute regional differences. We are aware, however, that some researchers might have different intuitions on this matter ( see Fischer, 1989, p. 874).

\footnotetext{
${ }^{2}$ In Experiments 2 and 3 we changed the definition of South slightly so that the South could be described by its "cultural geography" instead of its census classification (Gastil, 1971; Zelinsky, 1973). Thus, in Experiments 2 and 3 the South was defined as states having a score of 25 or more on Gastil's (1971) Southernness Index, indicating that they were either part of the Old South or were settled overwhelmingly by southerners. The list of states with a Southernness Index of 25 or morc is essentially the same as that of Experiment 1, except that Maryland and Delaware do not have Index scores of 25 or more, whereas Arizona and New Mexico do. We expanded our definition of suburban Washington, DC in Experiments 2 and 3 to exclude any student who defined himself as coming from a DC suburb. To increase our southern sample size, we considered Missouri and Nevada southern in Experiment 2 and considered Missouri, Nevada, Kansas, Colorado, and Maryland southern in Experiment 3, because these are states that border the South or Southwest and have southernness Indexes of 20 , indicating that they were settled substantially by southerners. Finally, in Experiment 3, to increase the size of the participant pool, we allowed current Michigan residents to be in the study so that we might recruit participants who had grown up in the South and then moved into the state. Expanding the definition of southerner was necessary to get enough participants, but we should also add that relaxing the criteria for southernness would generally work against our hypothesis.
} 


\section{Procedure}

Students came to the laboratory of the Institute for Social Research, where they were informed that the experiment concerned the effects of "limited response time conditions on certain facets of human judgment." After an initial introduction to the experiment, participants were told to fill out a short demographic questionnaire and were asked to take it to a table at the end of a long, narrow hallway.

As the participant walked down the hall, a confederate of the experimenter walked out of a door marked "Photo Lab" and began working at a file cabinet in the hall. The confederate had to push the file drawer in to allow the participant to pass by him and drop his paper off at the table. As the participant returned seconds later and walked back down the hall toward the experimental room, the confederate (who had reopened the file drawer) slammed it shut on seeing the participant approach and bumped into the participant with his shoulder, calling the participant an "asshole." The confederate then walked back into the "Photo Lab." Two observers were stationed in the hall. They appeared to be working on homework, paying no attention to the goings-on in the hall. One (male) observer was seated on the floor in a location where he could glance up and see the participant's face at the moment he was bumped. The other (female) observer was sitting at the table at the end of the hall where she could glance at the participant's face if he turned around (which occurred about $86 \%$ of the time across Experiments 1 and 3 ). Both observers could hear everything the participant said and could read his body language (though from different perspectives). Immediately after the bumping incident, the observers rated the participant's emotional reactions on 7-point scales. The reactions of anger and amusement were the ones of greatest interest, but observers also rated how aroused, flustered, resigned, or wary participants seemed. The correlation for the two observers' judgments was .52 for amusement ( $p<$ $.001)$ and .57 for anger $(p<.001)$. Observers also rated the effectiveness of the bump. There was no North-South difference on this rating, $t(41)$ $<1$. (Observers, of course, did not know the regional origin of the participant.) Participants who were assigned to the control condition completed the same procedures without being bumped. (Obviously, there were no observers and hence no ratings of emotional reaction in the control condition.)

After the participant returned to the room, the judgment tasks began. The first task was a word completion task, in which the participant was given a string of letters ( e.g., _. ight or gu_._) that he could complete either in a hostile way (e.g., fight or gun) or a nonhostile way (e.g., light or gum). The second task was a face rating task, in which the participant tried to guess which emotion was being expressed in a series of photographs of faces: anger, fear, disgust, sadness, or happiness. The third task was a scenario completion task, in which the participant needed to fill in the beginning or ending of a story. In one scenario, a man was rescued by an ambulance, and the participant was asked to fill in the beginning of the story. The other scenario involved issues of affront and challenge. The scenario began:

It had only been about twenty minutes since they had arrived at the party when Jill pulled Steve aside, obviously bothered about something.

"What's wrong?" asked Steve.

"It's Larry. I mean, he knows that you and I are engaged, but he's already made two passes at me tonight."

Jill walked back into the crowd, and Steve decided to keep his eye on Larry. Sure enough, within five minutes Larry was reaching over and trying to kiss Jill.

Participants were asked to complete the ending to this story. ${ }^{3}$

After all tasks were completed, participants were thoroughly debriefed and reconciled with the bumper. The debriefer explained why the research was important and why the deception and insult were used. The bumper met the participants and talked with them to make sure they were not upset or angered by the experience. Informal conversations made it clear that participants were not unhappy with the treatment accorded them and understood the reasons for it. To establish this in a more formal way, we asked several questions of participants at the end of the debriefing in Experiment 2. We asked participants how interested they were by the experiment on a scale that ranged from 0 (not at all) to 7 (extremely). The modal answer was 7 , and the mean was 5.8 . We asked how glad participants were that they had been in the experiment. The mode again was 7 , with $96 \%$ of participants at or above the midpoint on the scale. Participants also were asked how angry they were at having been in the experiment. Eighty-nine percent of participants answered 0 , and no participant answered as high as the midpoint on the scale. In fact, on every measure, insulted participants were more favorable toward the experiment than controls.

\section{Results and Discussion}

\section{Emotional Reactions}

Northerners and southerners differed in how angry or amused they appeared to be after the bump. Observers rated northern participants as significantly more amused by the bump than southern participants (northern $M=2.77$, southern $M=1.74$ ), $t(41)=2.85, p<.01$, and southern participants tended to be more angry than northern participants (northern $M=2.34$, southern $M=3.05), t(41)=1.61, .10<p<.15 .{ }^{4}$ Means and standard deviations for these and other key variables are presented in the Appendix.

We subtracted the amusement rating from the anger rating for each participant to show the very different reaction patterns of northerners and southerners. As may be seen in Table 1, the most common emotional reaction for northerners was to show more amusement than anger. The overwhelmingly dominant reaction for southerners was to show as much or more anger than amusement. There were no significant differences on how aroused, flustered, resigned, or wary participants seemed (all $t \mathrm{~s}$ $<1.1$, all $p s>.25)$.

\section{Projective Hostility}

We examined whether the insult would make southerners more hostile while leaving northerners unaffected.

Word completion. The insult did not significantly affect either southerners, $t(39)<1.2, p>.25$, or northerners, $t(40)<$ $1.2, p>.25$. There was also no main effect for either region or insult ( both $F \mathrm{~s}<1$ ).

\footnotetext{
${ }^{3}$ Participants were also given another neutral scenario in which a man goes to an ice skating rink. This scenario was not analyzed with the others because only 1 participant completed the story with a violent event.

${ }^{4}$ All $p$ levels reported in this article are two-tailed.

${ }^{5}$ Our theory clearly predicts that southerners would be more angry at the insult, whereas northerners would be more likely to be amused. However, on some interpretations of our theory it might also be expected that, in addition, southerners would be more aroused, whereas northerners would be more resigned. Differences on ratings for resigned and aroused in fact were small. However, adding them in an index with angered and amused still leaves significant differences between southerners and northerners. An index of anger + arousal - amused - resigned was significant at $p<.05, F(1,41)=4.01$. (Means were: southerners $=3.90$, northerners $=2.11$ )
} 
Table 1

Observers' Ratings of Northern Versus Southern Participants' Reactions to Insult

\begin{tabular}{lcc}
\hline Participants & $\begin{array}{c}\text { Percentage anger ratings } \\
\text { as high or higher than } \\
\text { amusement ratings }\end{array}$ & $\begin{array}{c}\text { Percentage amusement } \\
\text { ratings higher than } \\
\text { anger ratings }\end{array}$ \\
\hline Northern & 35 & 65 \\
Southern & 85 & 15 \\
\hline
\end{tabular}

Face ratings. Southerners were not more likely to project anger, disgust, fear, happiness, or sadness onto the faces shown to them after the insult than were northerners (all interaction $F$ s $<1$ ). There was again no main effect of either region or insult for any of the ratings (all $p s>.25$ ), except for happiness. Both control and insulted southerners were less likely to project happiness onto the faces than northerners were, $F(1,76)=$ $5.19, p<.05$.

Scenario completions. There were no region, insult, or interaction effects on how likely participants were to begin the "ambulance" scenario with interpersonal violence (all $p s>$ .15). In sum, none of the projective measures showed a differential impact of the insult as a function of the participant's regional origin. This was not true, however, for the insult scenario.

\section{Insult Prime Scenario}

For the scenario describing the attempted pass at the fiancee, there was a significant interaction between region and insult. If southerners were insulted, they were much more likely to end the scenario with violence, whereas northerners were unaffected by the insult. Seventy-five percent of insulted southerners completed this scenario with events in which the man injured or threatened to injure his challenger, whereas only $20 \%$ of control southerners did so, $\chi^{2}(1, N=40)=12.13, p<.001$. Northerners were unaffected by the manipulation, being somewhat less likely to conclude this scenario with violence if they had been insulted $(41 \% \mathrm{vs}$. $55 \%) ; \chi^{2}(1, N=42)=0.83, p>.25$. To examine the interaction between region and insult, we performed an analysis of variance (ANOVA) on a three-level variable (no violence, violence suggested, actual violence). Higher numbers indicated greater violence, and means were: southern insult $=2.30$, southern control $=$ 1.40 , northern insult $=1.73$, and northern control $=2.05$, interaction $F(1,78)=7.65, p<.005)$. $^{6}$

Experiment $I$ indicated that southerners were likely to see the insult as a cause for anger rather than amusement, whereas northerners were not much affected by the insult, taking it as a cause more for amusement than for anger. In addition, southerners (but not northerners) were much more likely to complete the "affront" script with violence if they had been insulted than if they had not. This greater hostility on the part of insulted southerners was manifested only in response to the affront prime, however. Insulted southerners were no more likely to project hostility onto neutral stimuli than were other particjpants. These findings indicate that an insult may make a southern male angry and may lower his threshold for anger in response to subsequent affronts, without necessarily producing hostility in response to innocuous stimuli.

\section{Experiment 2}

In Experiment 2 we explored whether, for southerners, responses to insult go beyond annoyance and mere cognitive priming for aggression and are accompanied by physiological changes of a sort that might mediate genuine behavioral aggression. We also attempted to test whether insulted southern participants would be motivated to demonstrate their toughness. We examined four major variables.

\section{Physiological Measure of Stress}

To measure how upset or stressed the participant became, we examined the cortisol level of the participant before and after the bump. Cortisol is a hormone associated with high levels of stress, anxiety, and arousal in humans and in animals (Booth, Shelley, Mazur, Tharp, \& Kittok, 1989; Dabbs \& Hooper, 1990; Kirschbaum, Bartussek, \& Strasburger, 1992; Leshner, 1983; Popp \& Baum, 1989; Thompson, 1988). If southerners are more upset by the acute stress of the insult, they should show a rise in cortisol levels compared with control participants. If northerners are relatively unaffected by the insult, as they seemed to be in Experiment 1, they should show little or no rise in cortisol levels compared with control participants.

\section{Physiological Measure of Preparedness for Future Aggression}

To measure how prepared for future challenges the participants became, we examined their testosterone levels before and after the bump. Testosterone is a hormone associated with aggression and dominance behavior in animals and both male and female humans. The causation seems to go both ways: High levels of testosterone facilitate dominance or aggressive behaviors, and successful dominance encounters lead to increases in

\footnotetext{
${ }^{6}$ Throughout this article we use a contrast comparing insulted southerners with all other groups. This contrast of $+3,-1,-1,-1$ was significant for the analysis of the "attempted kiss" script at the $p<.02$ level, $t(78)=2.46$. We also analyzed the residuals from the $+3,-1,-1$, -1 contrast to see if there was any significant variation "left over" after the contrast effect had been taken into account. To perform this calculation, we computed an $F$ test with mean square of the residual $\div$ mean square error. The mean square of the residual was computed as: (sum of squares between groups - sum of squares contrast) $\div 2$ (because there were 2 degrees of freedom for the residual). This residual was marginally significant, indicating that there was still some betweengroup variation unaccounted for by our model (for the residual: . $10>$ $p>.05, F[2,78]=2.56$ ). Furthermore, to examine the interaction between region and insult and type of measure used (affront scenario vs. neutral scenario), we calculated the difference between the participant's violent completion of the "attempted kiss" script and his completion of the ambulance script. (To make the comparison, both the ambulance script and the "kiss" script were put on the same 1-2 scale [no violence vs. violence], and a difference score was computed. Means were: southern insult $=0.65$, southern control $=0.20$, northern insult $=0.23$, northern control $=0.45$, with higher numbers indicating more violence on the kiss script relative to the ambulance script.) The interaction for the difference score was significant at $p<.003, F(1,78)=9.73$. Again, the $+3,-1,-1,-1$ contrast was significant at $p<.006, t(78)=$ 2.85. The residual, after the effect of the contrast was removed, was not significant, $p>.15, F(2,78)=1.65$.
} 
testosterone (Booth et al., 1989; Dabbs, 1992; Elias, 1981; Gladue, 1991; Gladue, Boechler, \& McCaul, 1989; Kemper, 1990; Mazur, 1985; Mazur \& Lamb, 1980; Olweus, 1986; Popp \& Baum, 1989). Research has suggested that testosterone plays a role in preparing participants for competitions or dominance contests ( Booth et al., 1989; B. Campbell, O'Rourke, \& Rabow, 1988, cited in Mazur, Booth, \& Dabbs, 1992; Dabbs, 1992; Mazur et al., 1992; see also Gladue et al., 1989, p. 416; but see Salvador, Simon, Suay, \& Llorens, 1987). Higher testosterone levels may facilitate the aggressive behaviors and display of dominance cues that make one act and even look tougher (Dabbs, 1992, pp. 311-313; Mazur, 1985). In addition, testosterone may raise fear thresholds. In male rats, injections of testosterone act as an anxiolytic agent, reducing the rat's fear of novel environments (Osborne, Niekrasz, \& Seale, 1993). It would obviously be useful in challenge or competition situations if this fearreducing effect were to occur in humans.

If southerners respond to the insult as a challenge and prepare themselves for future aggression or dominance contests, we might expect a testosterone increase after the bump. If northerners are relatively unaffected, we would not expect their testosterone levels to rise very much.

\section{Desire of the Participant to Demonstrate Toughness}

We also gave participants an opportunity to demonstrate their toughness by committing themselves to take shock in an "electric shock stress test." Participants had a public opportunity to demonstrate their toughness in front of two male confederates, and they had a private opportunity to reconsider their commitment after the confederates left the room. We examined the public minus private discrepancy in shock taking as a measure of the participant's desire to demonstrate toughness to his audience. We anticipated that southerners would show a greater desire to demonstrate toughness after being insulted than would northerners.

\section{Interpretation of Ambiguous Stimuli}

In Experiment 1, insulted southerners did not project more hostility onto neutral stimuli, but they did project more hostility onto the scenario in which a clear affront was offered. In Experiment 2 we examined whether insulted southerners would project more hostility onto ambiguous scenarios in which there is only the possibility that an affront or challenge is being offered. Again, we included these ambiguous stimuli as exploratory variables to see how general or how specific the effect of the insult would be.

In Experiment 2 we also examined the importance of the public versus private nature of the insult, predicting that all in sult effects would be greater if the insult were carried out publicly.

\section{Method}

\section{Participants}

Participants were 173 white male undergraduates ( 111 northern, 62 southern) at the University of Michigan who were recruited by telephone and paid $\$ 10$. Again, students were considered southern if they had spent at least 6 years in the South. All other students were consid- ered northern. On average, southern participants had spent $81 \%$ of their lives in the South, compared with northern participants, who had spent only $3 \%$ of their lives in the South. Again, Black, Jewish, Hispanic, and Michigan-resident students were excluded.

\section{Procedure}

Participants were met in the laboratory by an experimenter who explained that the experiment concerned people's performance on tasks under various conditions. The experimenter said that she would be measuring the participant's blood sugar levels throughout the experiment by taking saliva samples. To get a baseline measurement, the participant was given a piece of sugarless gum to generate saliva, a test tube to fill to the 5-mL level, and a brief questionnaire to fill out as he provided the first saliva sample.

After the saliva sample was given, the participant was sent down the hall to drop off his questionnaire and was bumped and insulted as described in Experiment 1. The participant was either bumped publicly, bumped privately, or not at all. In the public condition, there were two witnesses to the insult. Both witnesses were confederates who were identified as fellow participants by the experimenter before the participant began his walk down the hall. Both observers made eye contact with the participant so that he knew they had witnessed the incident. In the private condition, there were no observers in the hallway. In the control condition, the participant was not bumped or insulted.

As the participant walked down the hall, he continued to chew the sugarless gum and was told not to talk while he had the gum in his mouth. This was to keep the participant from talking to observers after the insult in the public condition. As witnesses to the insult, the public observers rated the participant's emotional reaction to the bump. No private observation could be made because there were no observers in the hall for the private bump in this experiment. (In all conditions, observers and confederates were, of course, aware of condition but did not know whether the participant was a southerner or a northerner.)

After a few minutes, the participant and two confederates were called to the experimental room. In the public condition the confederates were the people who had seen the participant be insulted. The experimenter explained that they would be performing mechanical aptitude tasks while taking the electric shock stress test. She said that the test was "a great indicator of general physical and mental toughness" and that the U.S. Air Force administers it to all its fighter pilots. She explained that participation was optional but that if participants chose to take part, they would receive one shock a minute for $10 \mathrm{~min}$ at a level of their choice between 10 and 250 volts. She asked the two confederates how many volts they would like to take. One asked for 75 volts, the other for 25. The participant was then asked for his choice.

Participants and confederates filled out a medical inventory to see if they could continue with the procedure. The experimenter then took the two confederates out of the experimental room, ostensibly to get them set up in their separate rooms. The participant was then asked to give another saliva sample. On average, this second sample was given 13 min after the first.

After a few minutes, the experimenter returned and informed the participant that the confederate who selected 25 volts could not continue with the experiment. (Participants presumably would reckon this was for health reasons.) The experimenter allowed the participant the opportunity to switch to the confederate's 25 -volt level if he wanted. In the case of $71 \%$ of participants, the 25 -volt level was lower than the one they had selected for themselves. Each participant's choice constituted his private level of commitment to electric shock.

After the participant either changed his level or held to it, the experimenter asked him to fill out an "opinions test." This questionnaire had a number of scenarios that were ambiguous with respect to whether an insult had been delivered. In one scenario, for example, one character cuts another off as they are driving down the road. For each situation, the participant was asked to guess the likelihood of either a physical 
fight or a verbal argument occurring. After the participant finished the questionnaire, he was asked to give another saliva sample. On average, this third sample was given $25 \mathrm{~min}$ after the first. (We timed the second and third samples at these intervals after consulting with experts who believed that testosterone changes could be detected in saliva between 10 and $30 \mathrm{~min}$ after the bump).

Participants were extensively debriefed and reconciled with the bumper as in Experiment 1. No participants were actually shocked during the experiment.

\section{Assays}

Saliva samples were frozen at $-20^{\circ} \mathrm{F}$ so they could be assayed later for testosterone and cortisol by the University of Michigan Reproductive Sciences Program. ${ }^{7}$ Median variance ratios for the assays ranged from .01 to .04 . Split-half reliabilities for these assays were above .85 .

\section{Results}

We predicted that publicly insulted participants would show a more extreme pattern of responses than privately insulted participants. However, this did not happen, so we collapsed publicly and privately insulted participants into one insult condition. ${ }^{8}$

\section{Emotion Ratings}

Experiment 2 (as well as Experiment 3, which is reported subsequently) yielded weak and inconsistent results regarding the emotional reaction to the bump. We believe this was because of the requirements to chew gum and not to talk in Experiments 2 and 3 , which prohibited the free expression of emotion. Of course, this is a post hoc explanation, and the results of Experiment 1 regarding anger and amusement must be treated with caution until subsequent research replicates the findings of Experiment 1 in ecologically natural circumstances. ${ }^{9}$

\section{Cortisol Levels}

We averaged the two postbump measurements and then computed a change score: (average postbump cortisol level - prebump cortisol level $) \div$ (prebump cortisol level).${ }^{10}$ As may be seen in Figure 1, cortisol levels rose $79 \%$ for insulted southerners and $42 \%$ for control southerners. They rose $33 \%$ for insulted northerners and 39\% for control northerners. We had predicted that insulted southerners would show large increases in cortisol levels, whereas control southerners and both insulted and control northerners would show smaller changes. This was because, in the absence of provocation, there was no reason to assume the cortisol levels of southerners would rise more than the cortisol levels of northerners. It is only after provocation that we expected southerners to show cortisol increases over the level of northerners and over the level of control groups. The appropriate contrast to test this prediction is $+3,-1,-1,-1$. This contrast-indicating that the effect of the insult was seen only for southerners, not for northerners-described the data well and was significant, $t(165)=2.14, p<.03 .^{11}$ The residual betweengroup variance after the effect of the contrast was removed was not significant, $F(2,165)<1$ for the residual.

\section{Testosterone Levels}

As with cortisol, we averaged the two postbump measurements and then computed a change score: (average postbump testosterone level - prebump testosterone level) $\div$ (prebump testosterone level) ${ }^{12}$ As may be seen in Figure 2, testosterone levels rose $12 \%$ for insulted southerners and $4 \%$ for control southerners. They rose $6 \%$ for insulted northerners and $4 \%$ for control northerners. Again, we used the $+3,-1,-1,-1$ contrast indicating that change was expected only for insulted

\footnotetext{
${ }^{7}$ The cortisol assay was a Diagnostic Products Corporation Coat-ACount solid-phase ${ }^{125}$ I radioimmunoassay, based on cortisol-specific antibody immobilized to the wall of a polypropylene tube. The assay has been modified to accommodate saliva samples; controls are diluted 1:10 with water, and $200(\mu) \mathrm{L}$ of undiluted sample are required. The ${ }^{125}$ I-labeled cortisol competes for a fixed time with cortisol in the participant sample for antibody sites. The antibody stays immobilized while the supernatant is decanted; this terminates the reaction and isolates the antibody-bound fraction of the radiolabeled cortisol. The tube is counted in a gamma counter and converted via calibration curve to a measure of the cortisol present in the participant sample. The cortisol antiserum is highly specific for cortisol, with an extremely low crossreactivity to other naturally occurring steroids or therapeutic drugs that may be present in participant samples. The testosterone assay was a Diagnostic Products Corporation Coat-A-Count solid-phase ${ }^{125}$ I radioimmunoassay. The ${ }^{125}$ I-labeled testosterone competes for a fixed time with testosterone in the participant sample for antibody sites. The tube is then decanted, to separate bound from free, and counted in a gamma counter. The amount of testosterone present in the participant sample is determined from a standard curve, calculated in weight per volume $(\mu) \mathrm{g} / \mathrm{dl}$. The assay has been modified to accommodate saliva samples; controls are diluted $1: 10$ with water, and $200(\mu) \mathrm{L}$ of undiluted sample are needed. The antiserum is highly specific for testosterone, with very little crossreactivity to other compounds in participant samples; crossreactivity with dihydrotestosterone $<5 \%$.

${ }^{8}$ There were two instances in which there were slight interactions between region and the public versus private insult condition. Though the difference was not significant, privately insulted southerners showed a more extreme cortisol change than publicly insulted southerners, $t(36)$ $=1.27, p>.20$, whereas publicly and privately insulted northerners differed little ( $p$ for the interaction between region and public vs. private condition $=.11)$. Also, when we examined the public minus private shock-taking discrepancy, publicly insulted southerners were more likely to show a greater discrepancy than privately insulted southerners, whereas the reverse was true for northerners ( $p$ for the interaction between region and public vs. private condition $=.07$ ). We are unable to interpret this finding, however, because the large public-private discrepancy for southerners and small discrepancy for northerners was also found in the control condition, as well as in the public insult condition.

${ }^{9}$ The emotion data are discussed more fully in Cohen (1994).

${ }^{10}$ Results look quite similar if postbump cortisol levels are not averaged and changes from Time 1 to Time 2 and from Time 1 to Time 3 are examined separately (standard contrast for percentage change from Time I to Time $2: t[165]=1.89, p<.06$; standard contrast for percentage change from Time 1 to Time $3: t[166]=2.06, p<.04$ ).

${ }^{11}$ We also computed change scores using the formula: $\log$ (postbump cortisol level) $-\log$ (prebump cortisol level). Results were very similar, and the $+3,-1,-1,-1$ contrast was significant at $p<.03, t(165)=2.18$.

${ }^{12}$ Results look quite similar if postbump testosterone levels are not averaged and changes from Time 1 to Time 2 and from Time 1 to Time 3 are examined separately (standard contrast for percentage change from Time 1 to Time $2: t[165]=2.15, p<.03$; standard contrast for percentage change from Time 1 to Time $3: t[166]=1.88, p<.06)$.
} 
southerners. The contrast was significant at $p<.03, t(165)=$ $2.19 .{ }^{13}$ The residual after the contrast was removed was not significant, $F(2,165)<1$ for the residual.

\section{Shock Levels}

There was no effect for region, insult, or the interaction on the level of shock elected either in public or in private (all $p s>$ .10 ; see means in the Appendix). We computed the difference between how much shock the participant chose to receive in public minus how much he chose to receive in private. There was no effect of the insult and no interaction between insult and region (both $p s>.10$ ). There was, however, a significant main effect for region. Southerners, whether insulted or not, chose to receive more shock in public than they did in private ( mean for public-private difference for southerners $=13$ volts, for northerners $=4$ volts $), F(1,168)=4.86, p<.03$.

\section{Ambiguous Insult Scenarios}

There was no effect for region, insult, or the interaction on whether participants expected the ambiguous scenarios to end with either physical or verbal aggression (all $F \mathrm{~s}<1$ ).

\section{Discussion}

Experiment 1 indicated that although northerners were able to brush off the insult and remain unaffected by it, southerners were not able to do so and became primed for aggression if given

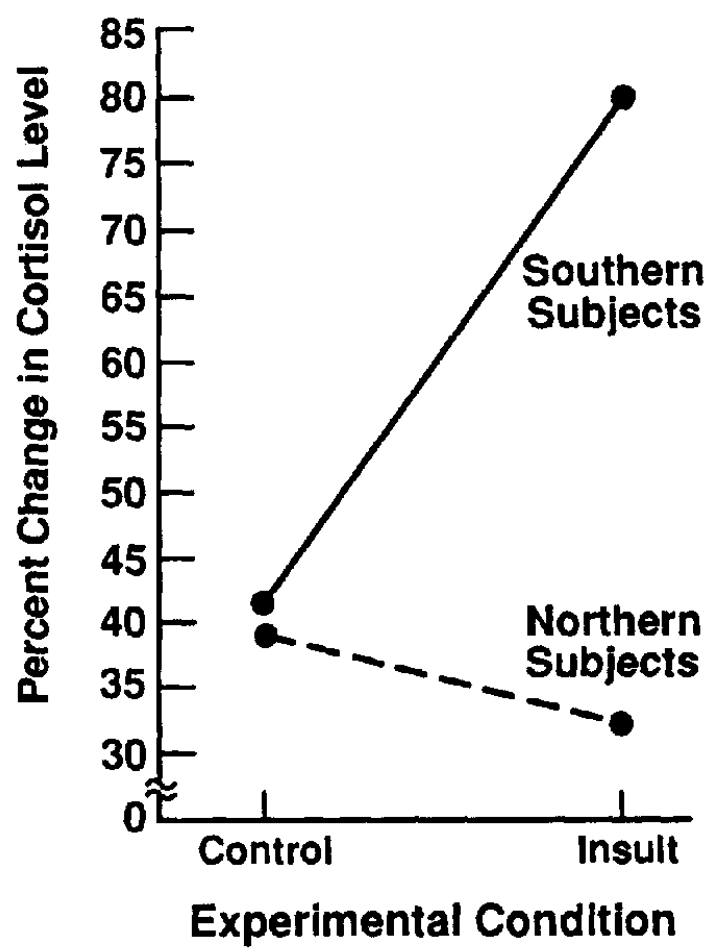

Figure 1. Changes in cortisol level for insulted and noninsulted southerners and northerners.

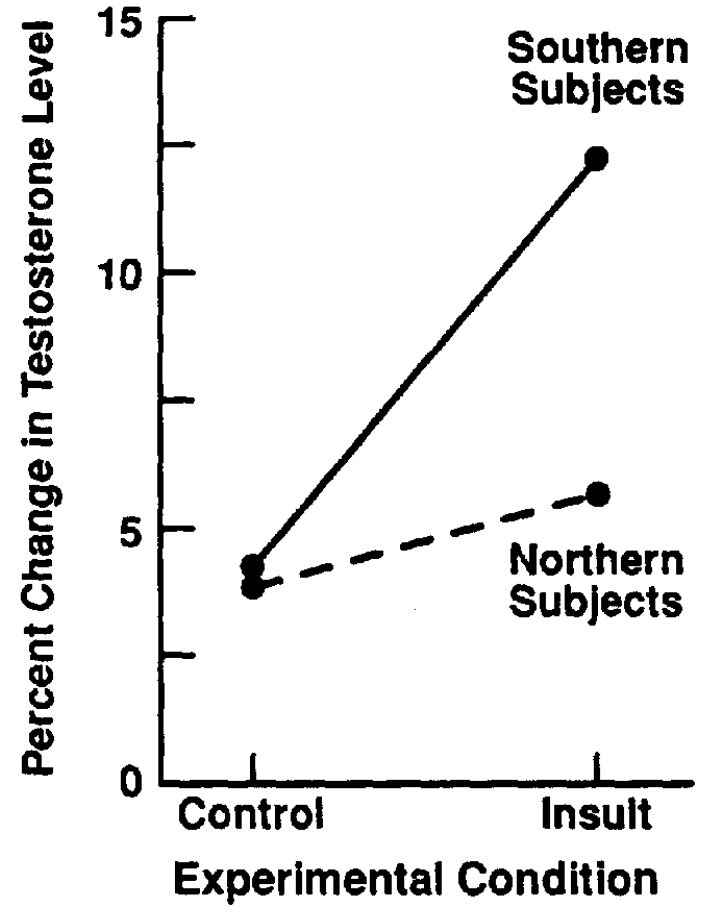

Figure 2. Changes in testosterone level for insulted and noninsulted southerners and northerners.

the right stimulus. Experiment 2 showed that southerners became upset and prepared for aggression on the physiological level. Southerners were more stressed by the insult, as shown by the rise in their cortisol levels, and more primed for future aggression, as indicated by the rise in their testosterone levels. Cortisol and testosterone levels of northerners were hardly affected by the insult.

There was no indication that the insult made southerners more cager to demonstrate toughness. However, the shock test may have been too artificial and an ecologically invalid measure of toughness for our participants. It would have been hard for them to translate shock levels into anything familiar, and it may not have seemed an appropriate forum for a toughness competition. We addressed this problem by giving participants a less artificial, more natural way to demonstrate toughness in Experiment 3.

The results for the ambiguous insult scenarios are consistent with the results for the ambiguous materials in Experiment 1. There is no evidence that insulted southerners were more likely than other participants to see malevolent intent in the protagonists' actions or to regard violence as an appropriate response to their actions. There are two plausible interpretations for this. The first is that it takes a clear-cut challenge or affront to bring out southerners' increased hostility and aggressiveness. The second is that our ambiguous measures were too uninvolving to pick up the effects: Perhaps we might have seen increased hos-

\footnotetext{
${ }^{13}$ We also computed change scores using the formula: $\log$ ( postbump testosterone level) $-\log ($ prebump testosterone level). Results were very similar, and the $+3,-1,-1,-1$ contrast was significant at $p<.05$, $t(165)=2.02$.
} 
tility on the part of insulted southerners if we had examined real behavior after putting participants in an ambiguously insulting (yet emotionally involving) live situation. We do not know which explanation is correct, but in any case the conclusion seems to be that measures that are unthreatening (either because they are uninvolving or because they are ambiguous with regard to issues of affront) will not elicit increased hostility from insulted southern participants.

\section{Experiment 3}

In Experiment 3 we tried to extend the results of Experiments 1 and 2 by exploring whether southerners would perceive an insult as damaging to their status and reputation (consistent with a culture-of-honor worldview) and would actually behave in more aggressive and domineering ways after an insult. We examined three major sets of variables.

\section{Perceived Effect of the Insult on One's Masculine Status}

In a public-insult condition, participants were bumped in front of an observer, whom they later met. The participant's task was to guess what that observer really thought of him. We expected southerners to think that the observer would see them as less masculine or tough after witnessing the insult. Northerners, however, should not feel that their status had been changed by the insult.

\section{Aggressive Behavior in a Challenge Situation After the Insult}

After the participant was bumped or not bumped, he continued walking down the long hallway. Another confederate-who was $6 \mathrm{ft} 3 \mathrm{in} .(1.91 \mathrm{~m})$ and $250 \mathrm{lbs}(114 \mathrm{~kg})$-appeared around the corner and began walking toward the participant at a good pace. The hall was lined with tables, so there was room for only one person to pass without the other person giving way. The new confederate walked down the center of the hall on a collision course with the participant and did not move (except at the last second to avoid another bumping).

In essence, we set up a "chicken" game similar to that played by American teenagers who drive at each other in their cars. In its many forms, "chicken" games are important in cultures of honor and situations in which participants try to establish their toughness for status or strategic advantage (Kahn, 1968; Schelling, 1963). The main dependent variable in this "chicken" game was the distance at which the participant decided to "chicken out" or give way to our confederate. We expected insulted southern participants to respond aggressively to the challenge and go farthest in this "game."

\section{Dominance Behavior in Subsequent Encounters After the Insult}

After the participant was bumped or not and had returned to the experimental room, he had a brief meeting with another confederate. This confederate, the "evaluator," was always the same person and was $5 \mathrm{ft} 6 \mathrm{in} .(1.67 \mathrm{~m})$ and $140 \mathrm{lbs}(64 \mathrm{~kg})$. The confederate rated the firmness of the participant's handshake and the degree of eye contact, and he made summary ratings of how domineering or submissive the participant was during the encounter, all on 7-point scales. We expected insulted southern participants to be more domineering and less submissive after the insult and northerners to be little affected by the insult.

After all other dependent measures were collected, we gave the participant two questionnaires asking about traditional "macho" behaviors. For example, the inventories asked the participant about how many pushups he could do, how much alcohol he had ever drunk in one night, and how fast he had ever driven a car. One of the questionnaires was "private," but the other was "public," as the participant believed he would have to discuss his answers with other experiment participants. We predicted that southerners would answer the questions in a more macho way after the insult, whether it had been public or private, and that the effect would be stronger on the public questionnaire.

Finally, participants were asked to fill out an extensive questionnaire about personal history and demographic status so we could examine the comparability of southern and northern participants on a variety of dimensions.

\section{Method}

\section{Participants}

Participants were 148 white male undergraduates ( 88 northern, 60 southern) at the University of Michigan who were recruited by telephone and paid $\$ 15$. Southerners were defined as anyone who had lived at least 6 years in the South; all other participants were considered northerners. On average, southern participants had spent $80 \%$ of their life in the South, compared with northerners, who had spent $5 \%$ of their life in the South. Black, Jewish, and Hispanic students were excluded.

\section{Procedure}

The experimenter told the participants that the experiment concerned people's personality and the contributions of nature versus nurture to personality. She explained that the participants would fill out a few personality inventories, answer some demographic questions, and provide a saliva sample that could be assayed for biological properties. She gave participants a demographic questionnaire as well as another filler questionnaire and had them provide a saliva sample as in Experiment 2. (Saliva samples were in fact not assayed later. They were collected to give credibility to the nature-versus-nurture cover story and to provide a pretext for the participant to chew gum so that he could be prohibited from talking after being bumped, as was the case in Experiment 2).

After the participant provided the saliva sample, the experimenter sent him down the hall to be bumped publicly, privately, or not at all. When the participant reached a specified point in the hall, he was either bumped or not; a few seconds later, a confederate covertly signaled the "chicken" confederate to appear. The "chicken" confederate walked toward the participant and estimated the distance in inches at which the participant gave way to him. He also rated the participant's appearance for how amused, threatening, angry, and so on he looked. (In trial runs, the "chicken's" estimate of distance correlated more than .90 with actual distance. The chicken, the obscrvers, and the evaluator were, of course, aware of the condition but did not know whether participants were southern or northern ).

When the participant returned to the room, the experimenter said that the experiment concerned "who you are" and that "one big part of who we are is who other people think we are." She explained the importance of first impressions for this and said that sometimes people 
are aware of the first impressions they make and sometimes they are not. She explained that the participant would have a brief meeting with another participant (actually the "evaluator" confederate). She added that the participant's task would be to guess what this other person really thought of him. The participant and his counterpart would be allowed to shake hands, but that was all. She said that no talking was allowed.

The experimenter explained that pairs of people would be meeting like this all semester. She added that to encourage as much accuracy and honesty as possible, the participant in the experiment who came closest to guessing what the other person thought of him would win $\$ 100$.

The experimenter then brought in the "evaluator" confederate, who shook hands with the participant. In the public bump condition, the evaluator was one of the witnesses to the bump. In the private bump condition, there had been no witnesses at all. In the control condition, there was, of course, no bump to observe.

After the brief handshake between the participant and the evaluator, the experimenter sent the evaluator out into the hall to record his impressions. Back in the experimental room, the experimenter explained that the participant would now have to guess what the evaluator thought of him. On a 1 -to- 5 scale, the participant guessed what the other person thought of him on dimensions such as cowardly-courageous, strongweak, and manly-not manly, as well as filler dimensions such as introverted-extroverted, attractive-unattractive, and so on.

After the participant completed these items, the experimenter asked him to rate himself on these dimensions as he really was. She explained that this was not for the $\$ 100$ prize but would merely help the research project. She then gave the participant the first "personality questionnaire" with the masculine protest items. After the participant was finished, she gave him the second "personality questionnaire" with another set of masculine protest items. She explained that this second questionnaire was relatively new and so would be the focus of a discussion between the participant and a few other undergraduate men. The second of these two questionnaires was thus the "public" questionnaire.

After the participant completed the second masculine protest questionnaire and then another demographic questionnaire, he was debriefed and reconciled with the bumper.

\section{Results}

Once again, the public versus private nature of the insult was not an important factor in participants' responses to the insult (all $p s>.15$ for the interaction between region and public vs. private condition) with the exception of participants' beliefs about how the "evaluator" confederate rated their personalities (interaction $p<.06$ ). Except for that variable, we collapsed over the public-private variable for purposes of analysis.

\section{"Chicken" Game}

As may be seen in Figure 3, the insult dramatically changed the behavior of southerners in the "chicken" game. Insulted southerners went much farther before "chickening out" and deferring to the confederate ( $37 \mathrm{in}$. [0.94 m]), compared with control southerners ( 108 in. [ $2.74 \mathrm{~m}]$ ). The insult did not much affect the behavior of northerners. The $+3,-1,-1,-1$ interaction contrast was significant at $p<.001, t(142)=3.45 .{ }^{14}$ The residual between-group variance after the contrast was removed was not significant, $F(2,142)=2.21, p>.10$.

We expected that insulted southern participants would be rated as walking in a more aggressive way and would exhibit more threatening behaviors (such as "staring down" our "chicken" confederate) and fewer deferential behaviors (such as

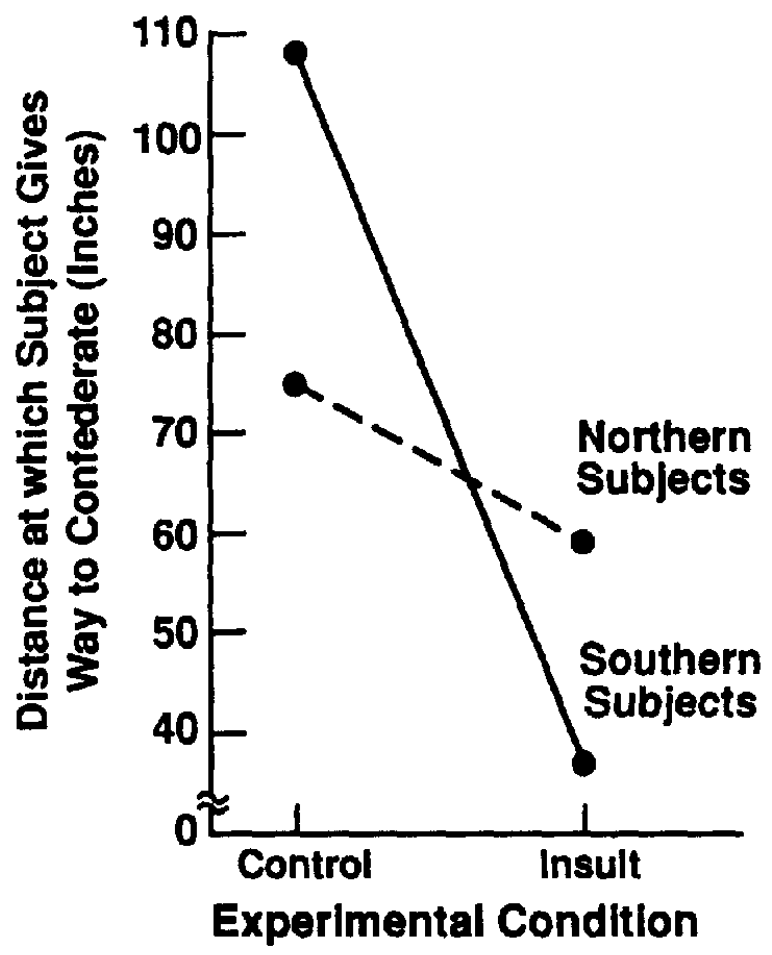

Figure 3. Distance at which the participant gave way to the confederate in the "chicken" game for insulted and noninsulted southerners and northerners.

looking down at the floor). However, ratings of the participant's manner and behaviors yielded inconsistent results and in general did not show the differential North-South effects due to the insult.

\section{Encounter With the Evaluator}

The evaluator's ratings for the firmness of the handshake and the degree to which eye contact was domineering were made on a 1-to-7 scale. As can be seen in Figure 4, southern participants gave firmer handshakes if they had been insulted than if they had not. Northerners were unaffected by the insult. The standard contrast was significant at $p=.06, t(144)=1.89$. Again, the residual after the contrast was removed was not significant, $F(2,144)<1$ for the residual. There was a weak and nonsignificant tendency for the insult to make southerners ( more than northerners) domineering in their eye contact $(.15<p<.20$ for the standard contrast $)$. The residual again was not significant, $p>.20, F(2,144)=1.34$ for the residual.

The rating for how domineering versus submissive the participant was during the encounter in general was computed by reversing the rating of how submissive the evaluator rated the participant to be and adding it to how domineering the evaluator rated him to be. As can be seen in Figure 5, insulted southerners were much more domineering than control southerners (mean

\footnotetext{
${ }^{14}$ Two outliers of more than $3 S D$ s from the mean were deleted from the analysis. The contrast remains highly significant if they are included, $t(144)=2.81, p<.01$.
} 
for insulted southerners $=3.90$, mean for control southerners $=$ 2.95.) Northerners were little affected by the insult (mean for insulted northerners $=3.61$, mean for control northerners $=$ 3.35.) The $+3,-1,-1,-1$ interaction contrast was significant at $p<.01, t(144)=2.52$. The residual for the contrast was not significant, $p>.20, F(2,144)=1.04$, for the residual.

Although dominance-related ratings showed the predicted effects, northerners and southerners were not differentially affected by the insult for ratings that did not concern dominance or submission. There was no differential effect of the insult on ratings for how friendly, uneasy, or embarrassed the participant was. There was also no differential effect of the insult on ratings of specific participant behaviors such as smiling, standing up, or verbally greeting the evaluator.

\section{Damage to Reputation}

To create a masculine or macho reputation scale, we combined the participant's guesses of what the other person thought of him on the dimensions manly-not manly, courageous-cowardly, assertive-timid, tough-wimpy, strong-weak, aggressivepassive, risk seeking-risk avoiding, and leader-follower. The dimensions were on 1-to-5 scales with higher numbers indicating more masculinity. The appropriate contrast here is the publicly insulted group (of southerners) with all other conditions. This is because the public insult condition is the only condition in which the confederate saw the participant get insulted. In the private insult condition the evaluator confederate did not witness the bump (even as a covert observer), and in the control condition there was no bump to observe.

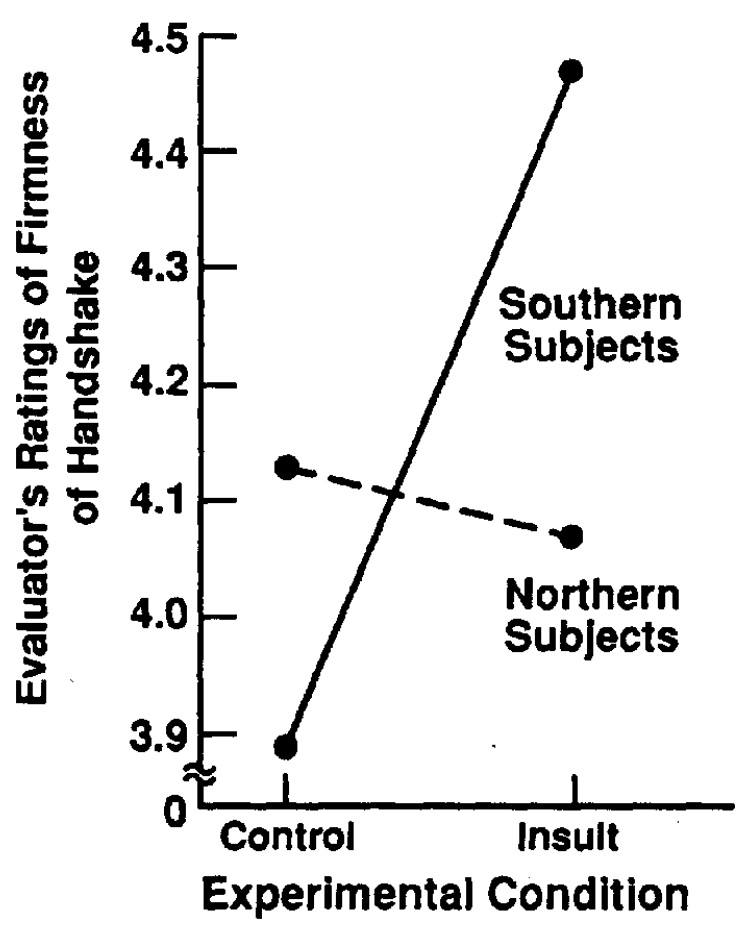

Figure 4. Firmness of handshake given by insulted and noninsulted southerners and northerners. Higher numbers indicate a firmer handshake.

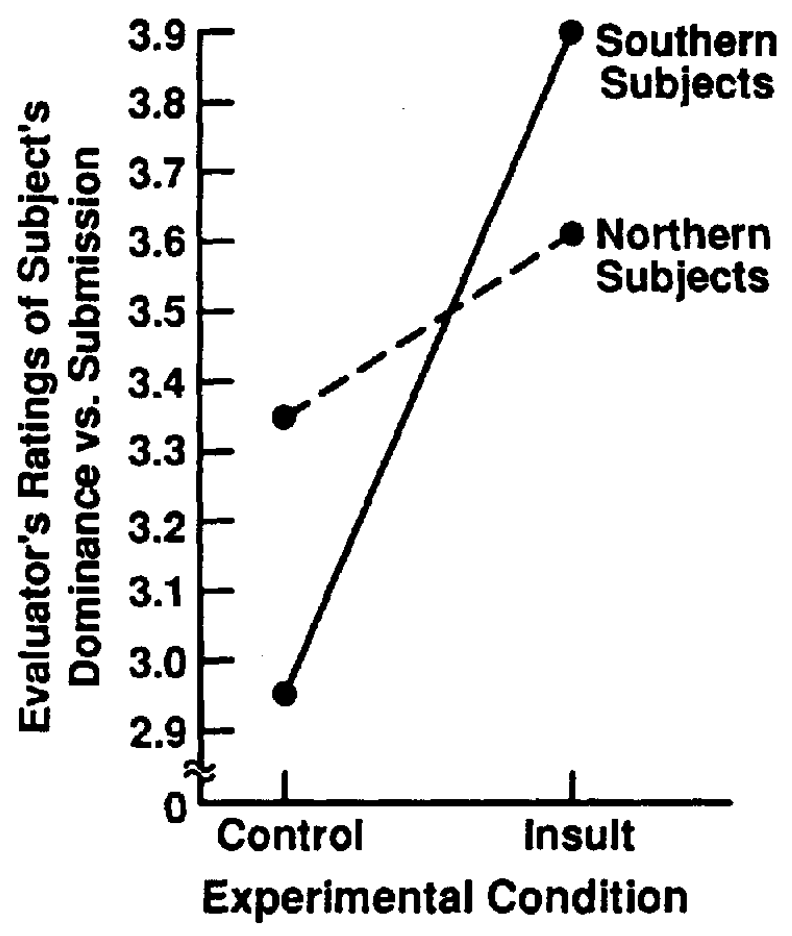

Figure 5. General domineering versus submissive impression given by insulted and noninsulted southerners and northerners. Higher numbers indicate more dominance.

As can be seen in Figure 6, control and privately insulted southerners and northerners believed they had equal status in the eyes of the evaluator on these dimensions. However, publicly bumped southerners were more likely to believe that their status was hurt in the eyes of the person who saw the insult, whereas northerners were hardly affected. The standard contrast was significant at $p<.01, t(144)=2.53 .{ }^{15}$ The residual for the contrast was not significant, $F(2,144)<1$ for the residual.

Moreover, damage to the participant's perceived reputation was limited to character traits associated with masculinity or machismo. We coded the 13 filler dimensions so that all were positively valenced and summed them to produce a positive impression scale that included none of the macho items. The public insult did not differentially affect how northerners and southerners thought the other person saw them on these nonmasculine dimensions $(p>.75) .^{16}$

\footnotetext{
is The 8 dimensions that composed our masculine reputation scale were selected by us a priori as the ones most relevant to the traditional definition of masculinity or machismo. To check the validity of our scale, we gave a list of the 21 dimensions to 35 white male non-Jewish undergraduates, asking them to rate how relevant these dimensions were to the traditional definition of "macho." Eleven dimensions were rated as at least "somewhat important" to the traditional definition. These 11 included the 8 we had selected and also the dimensions of athletic-unathletic, popular-unpopular, and insecure-confident. We reran our analyses using the 11 -dimension macho scale instead of the 8dimension macho scale. Means and significance levels changed very little. The $+3,-1,-1,-1$ contrast for how the participant thought the evaluator saw him was significant at $p<.02, t(144)=2.42$.

${ }^{16}$ To test for the interaction between region and insult and type of dimension (masculine vs. filler), we calculated a difference score be-
} 


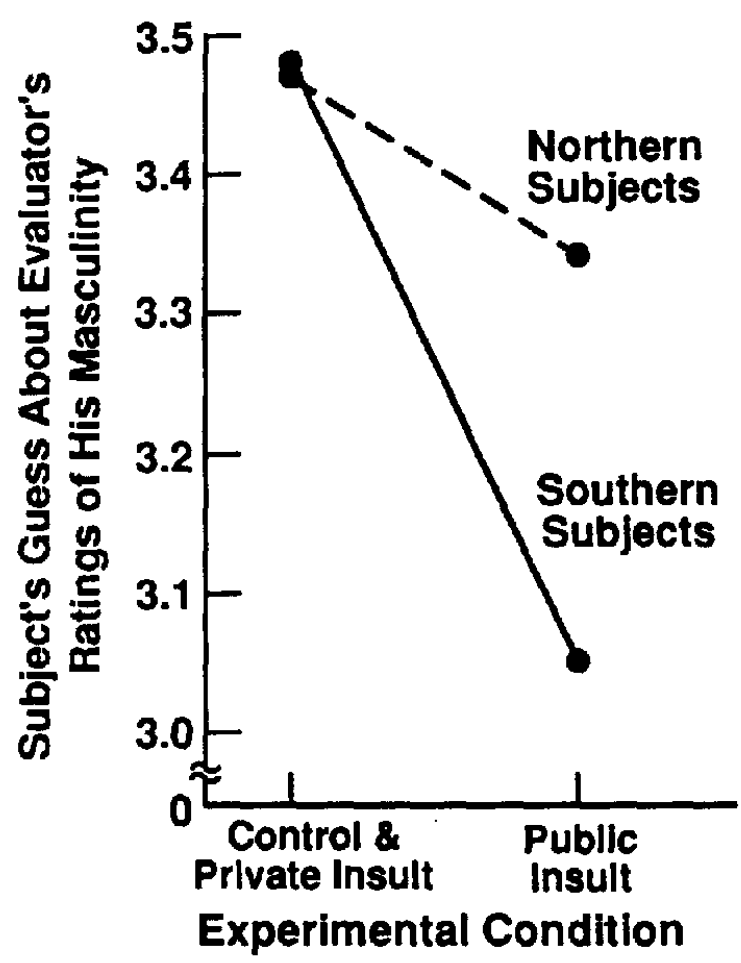

Figure 6 . Perceived masculine status of insulted and noninsulted southerners and northerners. Higher numbers indicate higher perceived masculine status.

The participant also rated himself on how he really was on all dimensions. Unlike the ratings of how the other person saw him, the participants' self-ratings for the macho items were not affected by the public insult for either northerners or southern$\operatorname{ers}(p>.75) .^{17}$

\section{Masculine Protest Questionnaires}

All items were standardized and summed. There was no effect for the questionnaire that was to be private, for the questionnaire that was to be public, or for the difference between these two questionnaires.

\section{Demographic Variables}

Demographic questions were asked of participants so that we could examine the comparability of the northern and southern samples. Northern and southern participants were remarkably similar on dimensions about which we asked. There were no significant differences between northern and southern participants in regard to: whether they had a religious preference, fre-

tween the macho items and the filler items (positively valenced). The contrast on the difference score was significant at $p<.04, t(144)=$ 2.07. The residual for the contrast was not significant, $F(2,144)$ for the residual $<1$. (Means were: southern insult $=0.43$, southern control $=$ 0.05 , northern insult $=0.05$, northern control $=0.08$. Higher numbers indicated more damage to reputation on the macho items, relative to the filler items.) quency of church attendance, whether they were now or ever had been in a fraternity, father's or mother's level of military service, family income, father's or mother's occupations, father's or mother's level of education, marital status of parents now and as participants were growing up, number of brothers, number of sisters, school of enrollment within the university, SAT scores, ACT scores, high school grade-point average, or participant weight (all $p s>.15$ ). Southern participants were, on average, taller than northern participants, $t(146)=2.75, p$ $<.01$, but the mean difference was only $1 \mathrm{in} .(2.54 \mathrm{~cm}$; mean for southern participants $=71.6 \mathrm{in}$. $[1.79 \mathrm{~m}]$, mean for northern participants $=70.5$ in. $[1.76 \mathrm{~m}])$. Southern participants were more likely to play a varsity sport in college, $t(144)=2.34, p<$ .02 , but not in high school. To make sure varsity athletics was not an important confound, we reran our analyses, eliminating the 2 northern athletes and the 7 southern athletes. Results changed very little when these participants were excluded. The $p$ levels for our standard contrast were: distance in "chicken" game, $p<.005, t(133)=2.98$; evaluator impression of dominance versus submission, $p<.04, t(135)=2.05$; evaluator rating of handshake, $p<.15, t(135)=1.58$; participant's estimation of the damage to his masculine reputation, $p<.04, t(135)$ $=2.08$.

\section{Discussion}

The results of Experiment 3 indicate that southerners who were insulted in front of others saw themselves as diminished in masculine reputation and status. Perhaps partly as a result, the insult produced more aggressive or domineering behavior. Although uninsulted southerners were, if anything, more polite than northerners, insulted southerners were much more aggressive than any other group.

The increased aggressiveness and the desire of insulted southern participants to reestablish themselves was demonstrated in the direct challenge situation of the "chicken" game with the 6ft-3-in. (1.91 m) confederate. Insulted southerners went much farther in the "chicken" game than did control southerners, whereas northerners were unaffected by the insult. Furthermore, the effect of the insult on southerners was demonstrated more subtly in the interpersonal encounter with the evaluator. Insulted southerners were much more domineering toward the evaluator than were control southerners, whereas northerners were again unaffected. The increased aggressive and dominance behavior of insulted southerners in Experiment 3 is consistent with the cognitive and physiological preparation for aggression and competition found in Experiments 1 and 2.

\footnotetext{
${ }^{17}$ To test for the interaction between region and insult and type of ratings (ratings for how others would see the participant vs. ratings for how the participant saw himself), we computed a difference score for the estimated "ratings" by the "other" minus ratings of the self. The contrast on the difference score was significant at $p<.003, t(144)=$ 3.00 . The residual for the contrast was not significant, $F(2,144)$ for the residual $<1$. (Means for the difference scores were: southern insult $=$ 0.48 , southern control $=0.08$, northern insult $=0.18$, northern control $=0.10$. Higher numbers indicate lower ratings from "others," relative to ratings of the self.) The public insult also did not differentially affect how northerners and southerners rated themselves on the nonmasculine dimensions $(p>.75)$.
} 


\section{General Discussion}

The findings of the present experiments are consistent with survey and archival data showing that the South possesses a version of the culture of honor. Southerners and northerners who were not insulted were indistinguishable on most measures, with the exception that control southerners appeared somewhat more polite and deferential on behavioral measures than did control northerners. However, insult dramatically changed this picture. After the affront, southern participants differed from northern participants in several important cognitive, emotional, physiological, and behavioral respects.

(a) Southerners were made more upset by the insult, as indicated by their rise in cortisol levels and the pattern of emotional responses they displayed as rated by observers (though the finding about emotional reactions must be considered tentative because of the failure to replicate it in Experiments 2 and 3, in which emotional expression may have been inhibited); (b) Southerners were more likely to believe the insult damaged their masculine reputation or status in front of others; (c) Southerners were more likely to be cognitively primed for future aggression in insult situations, as indicated by their violent completions of the "attempted kiss script" in Experiment 1; (d) Southerners were more likely to show physiological preparedness for dominance or aggressive behaviors, as indicated by their rise in testosterone levels; (e) Southerners were more likely to actually behave in aggressive ways during subsequent challenge situations, as indicated by their behavior in the "chicken" game; and (f) Southerners were more likely to actually behave in domineering ways during interpersonal encounters, as shown in the meeting with the evaluator.

It also is important to note that there were several measures-the neutral projective hostility tasks of Experiment 1, the ambiguous insult scenarios of Experiment 2, the shockacceptance measure of Experiment 2, and the masculine protest items of Experiment 3-on which northerners and southerners were not differentially affected by the insult. These null results suggest that the insult did not create a generalized hostility or perceived threat to self that colored everything southern participants did or thought. Measures that were irrelevant or ambiguous with respect to issues of affront and status, that were uninvolving because they were paper-and-pencil, and that were ecologically unnatural did not show an effect of the insult. Instead, the effect of the affront was limited to situations that concerned issues of honor, were emotionally involving, and had actual consequences for the participant's masculine status and reputation.

There are at least two explanations for why the insult produced a greater response from southerners. ${ }^{18}$ First, it could be that our bump and "asshole" insult were a greater affront to southerners, who are less accustomed to such rudeness than northerners are. Second, it could be that southerners have different "rules" for what to do once they are insulted. We believe both hypotheses to be true. Numerous observers have argued that southern culture is indeed more polite than northern culture (perhaps as a way of avoiding conflict), and some data from Experiment 3 support this assertion. We also believe, on the basis of survey data (Cohen \& Nisbett, 1994) and in-depth interview data collected with F. Lennox and J. Riad (Lennox et al., 1996), that southerners have different rules for how to re- spond to an affront. The expectations for what one should do when one's honor, self, or property are threatened are different in the South than in the North. For example, we found that southerners are more likely to believe that the appropriate response for a child who is being bullied is to fight back, and southerners are more likely to think it is right for a man to hit someone who insults him (Cohen \& Nisbett, 1994). Such responses seem better described as rules about what to do when provoked then as beliefs about what constitutes an insult.

However, data from the present experiments cannot untangle the two explanations-both of which are probably true in any case. Whatever the relative contributions of the two factors, we think the results help us understand something about the etiology of violence in the South and in similar cultures of honor. The results provide strong additional evidence that the insult is crucially important in such cultures. A male who is insulted but does not retaliate risks having his masculine reputation diminished, or at any rate believes that to be the case. When a challenging or highly status-relevant situation is encountered (usually but not necessarily in the ongoing insult situation itself), the person may lash out with violent or aggressive behavior to reassert him- or herself.

Strangely, results did not show that what we have called a "public" insult produced heightened aggression over and above a "private" insult. We do not believe this was because the public versus private nature of an insult is unimportant. Rather, we believe this was because of the weakness of our "public" manipulation, which amounted only to insulting participants in front of people they would never see again. Ideally, the insult should take place in front of one's acquaintances, friends, or family members to maximize the public nature of the affront.

Our laboratory experiments did not produce any truly violent behavior in our participants, so using these experiments as a direct analogy to homicide-producing processes in the South is inappropriate. Nevertheless, we believe the experiments might represent a microcosm of the insult-aggression cycle that is responsible for a good deal of violence in the South and in similar cultures of honor in the United States and elsewhere. A male who is affronted may be expected to respond with violence because he will be seen as "not much of a man" if he does not (Carter, 1950; Cohen \& Nisbett, 1994).

It is not hard to see how insult-aggression cycles lead to violence and death in real-life situations. Arguments that start over petty matters can quickly escalate into deadly conflicts once a challenge or insult has been issued. At that point, backing down marks one as a "wimp," and standing up for oneself becomes a matter of honor.

\footnotetext{
${ }^{18}$ Another possible explanation is that southerners-being in the minority at the University of Michigan-may be more reactive to the insult situation than northerners. Although this is a possible confound in these data, it is not a plausible explanation for similar results showing greater sensitivity to affronts from national surveys (Cohen $\&$ Nisbett, 1994), national field experiments (Cohen \& Nisbett, 1995), homicide records (Nisbett \& Cohen, 1996; Nisbett et al., 1994), and law and social policy analyses (Cohen, 1996). It seems parsimonious then to argue that the results of these experiments reflect the southern culture of honor, consistent with other work in this line of research. However, we do believe that replicating these results at a southern university, with northerners in the minority status, would be important.
} 
In the words of one Dallas homicide detective,

Murders result from little ol' arguments over nothing at all. Tempers flare. A fight starts, and somebody gets stabbed or shot. I've worked on cases where the principals had been arguing over a 10 cent record on a juke box, or over a one dollar gambling debt from a dice game." (Mulvihill, Tumin, \& Curtis, 1969, cited in Daly \& Wilson, 1988, p. 127)

As Daly and Wilson (1988) noted, however, these homicides are not really about petty slights: The "participants in these "trivial altercations' behave as if a great deal more is at issue than small change or access to a pool table" (p. 127). These contests escalate and become quite serious for participants because their status, reputation, and masculinity are on the line. Once the challenge or insult is offered, it is up to the affronted party to redeem himself by a display of toughness, dominance, or aggression.

Such concerns might appear outdated for southern participants now that the South is no longer a lawless frontier based on a herding economy. However, we believe these experiments may also hint at how the culture of honor has sustained itself in the South. It is possible that the culture-of-honor stance has become "functionally autonomous" from the material circumstances that created it (cf. Allport, 1937; Evans, 1970). Culture-ofhonor norms are now socially enforced and perpetuated because they have become embedded in social roles, expectations, and shared definitions of manhood.

Experiment 3 provides a suggestion about how culture-ofhonor norms might be enforced by one's peers. Insulted southerners saw themselves as shamed before people who witnessed their diminishment. Participants were realistic in their fears if it is indeed the case that southern observers would regard the episode as a serious put-down requiring a response. Perhaps our southern participants were thus being rational in their subsequent aggressive and domineering behavior, if they wanted to avoid the stigma of the insult before their peers.

The dynamics and specific mechanisms of the social enforcement of the culture of honor are important topics for future study. Until then, the present data, added to the homicide rate data and attitude data, offer support for three important points: (a) a version of the culture of honor persists in the South, and (b) the insult plays a central role in the culture of honor and the aggression that it produces, because (c) the affronted person feels diminished and may use aggressive or domineering behavior to reestablish his masculine status.

\section{References}

Allport, G. W. (1937). Personality: A psychological interpretation. London: Constable and Company.

Anderson, F. (1994). The code of the streets. The Atlantic Monthly, 5 , 81-94.

Ayers, E. L. (1984). Vengeance and justice. New York: Oxford University Press.

Booth, A., Shelley, G., Mazur, A., Tharp, G., \& Kittok, R. (1989). Testosterone and winning and losing in human competition. Hormones and Behavior, 23, 556-571.

Brearley, H. C. (1934). The pattern of violence. In W. T. Couch (Ed.), Culture in the South (pp. 678-692). Chapel Hill: University of North Carolina Press.

Brown, R. M. (1969). The American vigilante tradition. In H. Graham \& T. Gurr (Eds.), The history of violence in America (pp. 154-226). New York: Bantam.
Campbell, B., O'Rourke, M., \& Rabow, M. (1988). Pulsatile response of salivary testosterone and cortisol to aggressive competition in young males. Paper presented at the annual meeting of the American Association of Physical Anthropologists, Kansas City, MO.

Campbell, J. K. ( 1965). Honour and the devil. In J. G. Peristiany (Ed.), Honour and shame: The values of Mediterranean society (pp. 112175). London: Weidenfeld \& Nicolson.

Carter, H. (1950). Southern legacy: Baton Rouge: Louisiana State University Press.

Cohen, D. (1994). Insult, aggression, and the southern culture of honor: An "experimental ethnography." Unpublished doctoral dissertation, University of Michigan.

Cohen, D. (1996). Law, social policy, and violence: The impact of regional cultures. Journal of Personality and Social Psychology, 70. 961-978.

Cohen, D., \& Visbett, R. E. (1994). Self-protection and the culture of honor: Explaining southern violence. Personality and Social Psychol. ogy Bulletin, 20,551-567.

Cohen, D., \& Nisbett, R. E. (1995). Field experiments examining the culture of honor: The role of institutions in perpetuating norms. Manuscript submitted for publication.

Dabbs, J. M. ( 1992). Testosterone measurements in social and clinical psychology. Journal of Social and Clinical Psychology. 11, 302-321.

Dabbs, J. M., \& Hooper, C. H. (1990). Cortisol, arousal, and personality in two groups of normal men. Personality and Individual Differences, 11, 931-935.

Daly, M., \& Wilson. M. (1988). Homicide. Hawthorne, New York: Aldine de Gruyter.

Edgerton, R. (1971). The individual in cultural adaptation. Berkeley: University of California Press.

Elias, M. (1981). Serum cortisol, testosterone, and testosterone-binding globulin responses to competitive fighting in human males. $\mathrm{Ag}$. gressive Behavior, 7, 215-224.

Evans, R. 1. (1970). Gordon Allport. New York: E. P. Dutton.

Fischer, D. H. (1989). Albion's seed: Four British folkways in America. New York: Oxford University Press.

Fox, J. A., \& Pierce, G. L. (1987). Uniform crime reports (United States): Supplementary homicide reports, 1976-1983 [machinereadable data file]. Ann Arbor, MI: Inter-University Consortium for Political and Social Research.

Gastil, R. D. (1971). Homicide and a regional culture of violence. American Sociological Review, 36, 416-427.

Gilmore, D. D. (1990). Manhood in the making: Cultural concepts of masculinity: New Haven, CT: Yale University Press.

Gladue, B. A. (1991). Aggressive behavioral characteristics, hormones, and sexual orientation in men and women. Aggressive Behavior, 17, 313-326.

Gladue, B. A., Boechler, M., \& McCaul, K. D. (1989). Hormonal response to competition in human males. Aggressive Behavior, 15, 409-422.

Guerra, $N$. (in press). Intervening to prevent childhood aggression in the inner city. In J. McCord (Ed.), Growing up violent. New York: Cambridge University Press.

Ireland, R. M. (1979). Law and disorder in nineteenth-century Kentucky. Vanderbilt Law Review, 32, 281-299.

Kahn, H. (1968). On escatation: Metaphors and scenarios. Baltimore: Penguin Books.

Kemper, T. D. (1990), Social structure and testosterone. New Brunswick, NJ: Rutgers University Press.

Kirschbaum, C., Bartussek, D., \& Strasburger, C. J. (1992). Cortisol responses to psychological stress and correlations with personality traits. Personality and Individual Differences, 13, 1353-1357.

Kowalski, G. S., \& Peete, T. A. (1991). Sunbelt effects on homicide rates. Sociology and Social Research, 75, 73-79.

Lee, R. S. (1993). Machismo values and violence in America. Unpublished manuscript, Pace University. 
Lennox, F., Riad, J., Cohen, D., Dabbs, J., \& Nisbett, R. E. (1996). [Culture, aggression, and masculinity]. Unpublished raw data.

Leshner, A. 1. (1983). Pituitary-adrenocortical effects on intermale agonistic behavior. In B. Svare (Ed.), Hormones and aggressive behavior (pp. 27-38). New York: Plenum.

Mazur, A. (1985). A biosocial model of status in face-to-face primate groups. Social Forces, 64, 377-402.

Mazur, A., Booth, A., \& Dabbs, J. M. (1992). Testosterone and chess competition. Social Psychology Quarterly, 55, 70-77.

Mazur, A., \& Lamb, T. A. (1980). Testosterone, status, and mood in human males. Hormones and Behavior, 14, 236-246.

McCall, N. (1994). Makes me wanna holler. New York: Random House. McWhiney, G. (1988). Cracker culture: Celtic ways in the Old South. Tuscaloosa: University of Alabama Press.

Mulvihill, D. J., Tumin, M. M., \& Curtis, L. A. (1969). Crimes of violence (Vol. 11). Washington, DC: U.S. Government Printing Office.

Nisbett, R. E. (1993). Violence and U.S. regional culture. American Psychologist, 48, 441-449.

Nisbett, R. E., \& Cohen, D. (1996). Culture of honor: The psychology of violence in the South. Boulder, CO: Westview Press.

Nisbett, R. E., Polly, G., \& Lang, S. (1994). Homicide and regional U.S. culture. Unpublished manuscript, University of Michigan.

Olweus, D. (1986). Aggression and hormones: Behavioral relationship with testosterone and adrenaline. In D. Olweus, J. Block, \& $\mathbf{M}$. Radke-Yarrow (Eds.), Development of antisocial and prosocial behav. ior (pp. 51-72). Orlando, FL: Academic Press.

Osborne, R. E., Niekrasz, I., \& Seale, T. W. (1993). Testosterone in- duces rapid onset of anxiolytic-like behaviors in mice. Paper presented at the Evolution and Human Behavior Meeting, Buffalo, NY.

Peristiany, J. G. ( 1965). (Ed.). Honour and shame: The values of Mediterranean society. London: Weidenfeld \& Nicolson.

Pitt-Rivers, J. (1968). Honor. In D. Sills (Ed.), International encyclopedia of the social sciences (pp. 509-510). New York: Macmillan.

Popp, K., \& Baum, A. ( 1989). Hormones and emotions: Affective correlates of endocrine activity. In H. Wagner \& A. Manstead (Eds.), Handbook of social psychophysiology (pp. 99-120). Chichester, England: Wiley.

Reaves, A. L., \& Nisbett, R. E. (1994). The cultural ecology of rural White homicide in the southern United States. Unpublished manuscript, University of Michigan.

Salvador, A., Simon, V., Suay, F., \& Llorens, L. ( 1987). Testosterone and cortisol responses to competitive fighting in human males: A pilot study. Aggressive Behavior, 13, 9-13.

Schelling, T. C. (1963). The threat of violence in international affairs. Proceedings of the American Society of International Law (pp. 103115). Washington, DC: American Society of International Law.

Thompson, J. G. (1988). The psychobiology of emotions. New York: Plenum.

Wolfgang, M. E., \& Ferracuti, F. (1967). The subculture of violence. London: Tavistock.

Wyatt-Brown, B. (1982). Southern honor: Ethics and behavior in the Old South. New York: Oxford University Press.

Zelinsky, W. (1973). The cultural geography of the United States. Englewood Cliffs, NJ: Prentice Hall.

(Appendix follows on next page) 


\section{Appendix}

Means and Standard Deviations for Key and Exploratory Variables

\begin{tabular}{|c|c|c|c|c|c|c|c|c|}
\hline \multirow[b]{2}{*}{ Variable } & \multicolumn{2}{|c|}{ Southern insult } & \multicolumn{2}{|c|}{ Southern control } & \multicolumn{2}{|c|}{ Northern insult } & \multicolumn{2}{|c|}{ Northern control } \\
\hline & $M$ & $S D$ & $M$ & $S D$ & $M$ & $S D$ & $M$ & $S D$ \\
\hline \multicolumn{9}{|l|}{ Study 1} \\
\hline \multicolumn{9}{|l|}{ Bump reaction } \\
\hline Amused & 1.74 & 1.07 & & & 2.77 & 1.30 & & \\
\hline Angry & 3.05 & 1.48 & & & 2.34 & 1.40 & & \\
\hline Aroused & 4.24 & 1.15 & & & 4.05 & 1.08 & & \\
\hline Resigned & 1.64 & 0.74 & & & 1.50 & 0.60 & & \\
\hline Flustered & 2.02 & 1.03 & & & 1.77 & 0.77 & & \\
\hline Wary & 1.62 & 0.84 & & & 1.39 & 0.58 & & \\
\hline Violent word completion index & 0.73 & 0.25 & 0.65 & 0.19 & 0.66 & 0.28 & 0.74 & 0.14 \\
\hline \multicolumn{9}{|l|}{ Face projection } \\
\hline Anger face projection & 1.82 & 1.40 & 1.48 & 1.21 & 1.70 & 1.17 & 1.41 & 1.12 \\
\hline Disgust face projection & 1.94 & 1.50 & 1.60 & 1.21 & 1.58 & 1.22 & 1.70 & 1.27 \\
\hline Fear face projection & 1.12 & 0.92 & 0.96 & 0.92 & 1.27 & 0.78 & 1.07 & 0.91 \\
\hline Happy face projection & 0.49 & 0.51 & 0.52 & 0.52 & 0.69 & 0.68 & 0.93 & 0.67 \\
\hline Sad face projection & 1.37 & 1.22 & 1.70 & 1.30 & 1.83 & 1.19 & 1.73 & 1.19 \\
\hline \multicolumn{9}{|l|}{ Violent endings for ambulance script } \\
\hline (2-level variable) & 1.10 & 0.31 & 1.00 & 0.00 & 1.18 & 0.39 & 1.10 & 0.31 \\
\hline Violent endings for "attempted kiss" & & & & & & & & \\
\hline script (3-level variable) & 2.30 & 0.86 & 1.40 & 0.82 & 1.73 & 0.94 & 2.05 & 1.00 \\
\hline \multicolumn{9}{|l|}{ Study 2} \\
\hline Cortisol change & 0.79 & 1.58 & 0.42 & 1.27 & 0.33 & 0.64 & 0.39 & 0.56 \\
\hline Testosterone change & 0.12 & 0.24 & 0.04 & 0.21 & 0.06 & 0.17 & 0.04 & 0.14 \\
\hline Public shock taking & 64.49 & 47.83 & 77.73 & 54.42 & 68.45 & 44.54 & 57.97 & 46.09 \\
\hline Private shock taking & 52.44 & 46.90 & 63.64 & 57.59 & 60.74 & 46.62 & 61.22 & 57.40 \\
\hline \multicolumn{9}{|l|}{ Ambiguous scenarios--ending in } \\
\hline physical fight & 32.96 & 13.62 & 32.33 & 12.77 & 32.08 & 14.75 & 31.60 & 14.27 \\
\hline Ambiguous scenarios-ending in an & & & & & & 1384 & 6737 & 132, \\
\hline Study 3 argument & 53.99 & 12.70 & 56.01 & 14.80 & 56.47 & \multicolumn{3}{|c|}{ Study 3} \\
\hline Chicken distance & 37.43 & 45.17 & 107.95 & 89.27 & 58.67 & 71.99 & 75.23 & 58.19 \\
\hline Evaluator's rating of handshake & 4.46 & 1.36 & 3.89 & 0.94 & 4.07 & 1.15 & 4.13 & 1.26 \\
\hline \multicolumn{9}{|l|}{ Evaluator's rating of dominance } \\
\hline versus submission & 3.90 & 1.24 & 2.95 & 1.14 & 3.61 & 1.35 & 3.35 & 1.17 \\
\hline \multicolumn{9}{|l|}{ Evaluator's rating of domineering } \\
\hline eye contact & 3.51 & 1.45 & 2.79 & 1.36 & 3.49 & 1.48 & 3.13 & 1.50 \\
\hline \multicolumn{9}{|l|}{$\begin{array}{l}\text { Participant's estimate of evaluator's } \\
\text { perception of his masculinity }\end{array}$} \\
\hline and control) & 3.05 & 0.61 & 3.48 & 0.63 & 3.34 & 0.52 & 3.47 & 0.67 \\
\hline \multicolumn{9}{|l|}{ Masculine protest-public } \\
\hline $\begin{array}{l}\text { questionnaire } \\
\text { Masculine protest-private }\end{array}$ & -0.03 & 0.39 & -0.07 & 0.44 & 0.05 & 0.48 & 0.05 & 0.40 \\
\hline $\begin{array}{l}\text { Masculine protest--private } \\
\text { questionnaire }\end{array}$ & -0.09 & 0.40 & -0.05 & 0.40 & 0.03 & 0.47 & 0.02 & 0.37 \\
\hline
\end{tabular}

Received August 28, 1994

Revision received October 24, 1995

Accepted November 27, 1995 